\title{
A 3D-Printed Hybrid Water Antenna with Tunable Frequency and Beamwidth
}

\author{
Zeng-Pei Zhong ${ }^{1,2}$, Jia-Jun Liang ${ }^{1}\left(\mathbb{D}\right.$, Guan-Long Huang ${ }^{1,2,3, *(\mathbb{D}}$ and Tao Yuan ${ }^{1,2}$ \\ 1 College of Information Engineering, Shenzhen University, Shenzhen 518060, China; \\ zhongzengpei2016@email.szu.edu.cn (Z.-P.Z.); shuigpjd@163.com (J.-J.L.); wutenghua525@gmail.com (T.Y.) \\ 2 ATR National Key Laboratory of Defense Technology, Shenzhen University, Shenzhen 518060, China \\ 3 State Key Laboratory of Millimeter Waves, Nanjing 210069, China \\ * Correspondence: guanlong.huang@szu.edu.cn
}

Received: 22 August 2018; Accepted: 1 October 2018; Published: 3 October 2018

\begin{abstract}
A novel hybrid water antenna with tunable frequency and beamwidth is proposed. An L-shaped metallic strip is adopted as the feeding structure of the antenna in order to effectively broaden the operating bandwidth. The L-shaped strip feeder and a rectangular water dielectric resonator constitute the driven element. Five identical rectangular water dielectric elements are mounted linearly with respect to the driven element, which act as the directors and contribute to narrow the beamwidth. By varying the height of the liquid water level in the driven element, the proposed antenna is able to tune to different operational frequencies. Furthermore, it is also able to adjust to different beamwidths and gains via varying the number of director elements. A prototype is fabricated by using 3-D printing technology, where the main parts of the antenna are printed with photopolymer resin, and then the ground plane and L-shaped strip feeder are realized by using adhesive copper tapes. Measurement results agree well the simulation ones. A tunable frequency ranging from $4.66 \mathrm{GHz}$ to $5.65 \mathrm{GHz}$ is obtained and a beam steering along a fixed direction with a gain variation less than $0.5 \mathrm{~dB}$ is realized.
\end{abstract}

Keywords: water antenna; 3-D printing; tunable frequency; tunable beamwidth; dielectric resonator antenna

\section{Introduction}

Reconfigurable antennas, which can achieve more than one operational mode by mechanical or electronic approaches, are considered to be a good solution for the design of multifunctional antennas [1-12]. According to some available literatures, reconfigurable antennas based on $p-i-n$ diodes are the most traditional design with good property such as fast switching speed and compact volume [13,14]. Recently, fluidic reconfigurable antennas are very popular since the liquid materials are easy to control their physical lengths or dimensions so as to change the radiation characteristic of an antenna in terms of, e.g., the operational frequency [15,16], gain [17], and polarization [18]. On the other hand, owing to the fast development of 3-D printing technology and microfluidic technology, many liquid materials such as liquid-metal, liquid water can be widely used in the design of microwave antennas [19-22].

Compared to the electrically-controlled reconfigurable antennas, the liquid antennas have some attractive features such as continuous tunability, wide tunable range and better radiation efficiency. What is more, the fluidic antennas are especially suitable for high power link application as the tuning approach does not constrain the power handling capability of the antenna, unlike the tuning mechanism utilizing p-i-n diodes or circuit elements. 
In this paper, a novel hybrid water dielectric resonator antenna (DRA) with the ability of continuous tuning frequency and beamwidth. For water antennas reported in literature previously, the substrate and water container are made of two different materials. For example, FR- 4 or Rogers materials are frequently used as the antenna substrate, while the water containers are often formed by using a 3D printer [8-12]. Therefore, in order to complete the whole water antenna system, the antenna substrate and the water containers have to be glued together by using adhesive stuffs. However, this traditional assembly method increases the processing complexity and the risk of manufacturing error. Furthermore, an uncertain effect will also be introduced due to the adhesive material, worsening the performance of the antenna.

In order to improve the electric performance of a fluidic antenna, a seamless design method is proposed in this paper. The antenna substrate and the water container are all made by 3-D printing technology. Actually, the commonly used antenna substrates are low relative dielectric constant materials such as FR-4 or Rogers 5880 with dielectric constant from around 2.5-5. Therefore, the antenna substrate can be made by using 3-D printing technology instead of the traditional ways. The advantage of this method not only simplifies the design process, but also reduces the manufacturing error, which opens a new and reliable pathway to liquid antenna design. In this paper, a hybrid water directional antenna with tunable frequency and beamwidth is proposed as a proof-of-concept demonstrator.

\section{Antenna Configuration}

The motivation of this paper is to design a hybrid water DRA with tunable frequency and beamwidth. The configuration of the proposed hybrid water antenna is shown in Figure 1. There are one driven element and five identical director elements arranged along $x$-axis. In the whole antenna system, four parts are realized by using the 3-D printing technology, i.e., one driven element, five director elements (named D1, D2, D3, D4, D5), one antenna substrate, and six pairs of water inlets and outlets. The photopolymer resin, acting as the printing material, is tasteless and non-toxic. Furthermore, its relative dielectric constant is about 3 , which is very close to the permittivity of traditional resin materials. Therefore, it is suitable to be utilized as the antenna dielectric substrate.

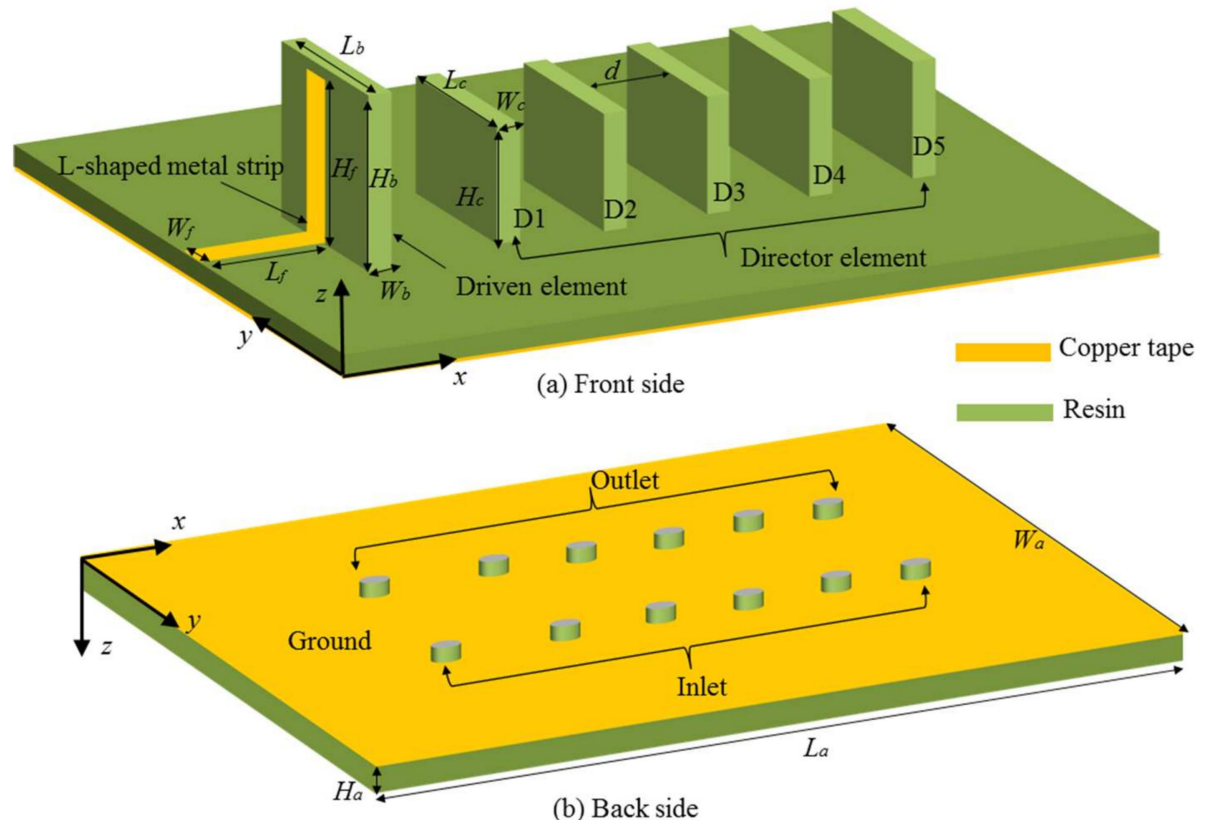

(b) Back side

Figure 1. Configuration of the proposed antenna: (a) Front side; (b) Back side.

As can be seen from Figure 1, the antenna substrate is a solid rectangular plate with dimensions of $L_{a} \times W_{a} \times H_{a}$. The water dielectric resonator (driven element) is a larger rectangular hollow block 
with dimensions of $L_{b} \times W_{b} \times H_{b}$, while the director consists of five smaller rectangular hollow blocks and each element is with the identical dimensions of $L_{c} \times W_{c} \times H_{c}$. For the hollow driven element and five director elements, their wall-thickness is fixed to $0.5 \mathrm{~mm}$, which is thin enough compared with a wavelength to eliminate its effects on the antenna's radiation performance.

In order to pump in and pump out water from the driven element and director elements, six pairs of inlet and outlet with radius of $1.2 \mathrm{~mm}$ are installed at the bottom of the substrate. Each inlet and outlet are connected to a small syringe. Namely, the driven element and director elements are independently connected to a pair of small syringes. In this paper, the small syringes are used as the manually-operated pressure controlling systems which are not included in the figure for simplicity. The final parameters of the proposed antenna are: $L_{a}=50 \mathrm{~mm}, W_{a}=30 \mathrm{~mm}, H_{a}=2 \mathrm{~mm}, L_{f}=12 \mathrm{~mm}$, $W_{f}=2 \mathrm{~mm}, H_{f}=12 \mathrm{~mm}, L_{c}=13 \mathrm{~mm}, W_{c}=3 \mathrm{~mm}, H_{c}=8.5 \mathrm{~mm}, d=3 \mathrm{~mm}$. More details regarding to the design and analysis of the proposed antenna will be revealed in the next section.

\section{Design Process and Performance Analysis}

In this section, the detailed design process of the proposed antenna is elaborated. Certain parameters influence the performance of the hybrid water DRA, including the height of the L-shaped metal strip feeder, the height of the distilled water level in the driven element and the number of the director elements. In order to investigate the effects of each factor, parametric studies are performed in the following subsections. During the analysis, only a target parameter is varied at a time to observe its effects on the antenna performance while other parameters are kept constant.

\subsection{Realization of Hybrid Water DRA with Frequency Tunable Characteristic}

In this work, the proposed hybrid water DRA technique generates resonances with the help of the water DRA and the L-shaped metallic strip feeder. The rectangular hollow block and the distilled water form a mixed dielectric resonator. When the height of the distilled water level is changed, the effective permittivity of the resonator can be tuned. Therefore, by properly choosing the height of the distilled water, a desirable effective permittivity can be obtained for the hybrid dielectric resonator. Throughout the simulation process, the dielectric constant of the distilled water and the resin is set to be 78 and 3, respectively.

The interested center resonant frequency in this work is targeted at $5 \mathrm{GHz}$. The dimensions of the proposed antenna are hereby optimized (see in Figure 1) based on this specific frequency. In order to offer a general physical insight on the design process, a simplified model of a single hybrid water DRA is utilized as an example. Figure 2 shows the simulation model of the hybrid water DRA. To better observe the internal structure, the side sectional view of the rectangular hollow block is given. As can be seen from Figure 2, the L-shaped metallic strip feeder includes two parts: a horizontal strip having a length of $L_{f}$ and a vertical strip having a height of $H_{f}$. The horizontal and vertical strips are coated on the surface of the substrate and the rectangular hollow block, respectively. Inside the rectangular hollow block, distilled water is pumped in or out by a pair of syringes. $H_{w}$ represents the height of the distilled water level. Note that of the existent of the syringes would not cause serious effect on the antenna performance, so that they are not considered in the simulation process. 


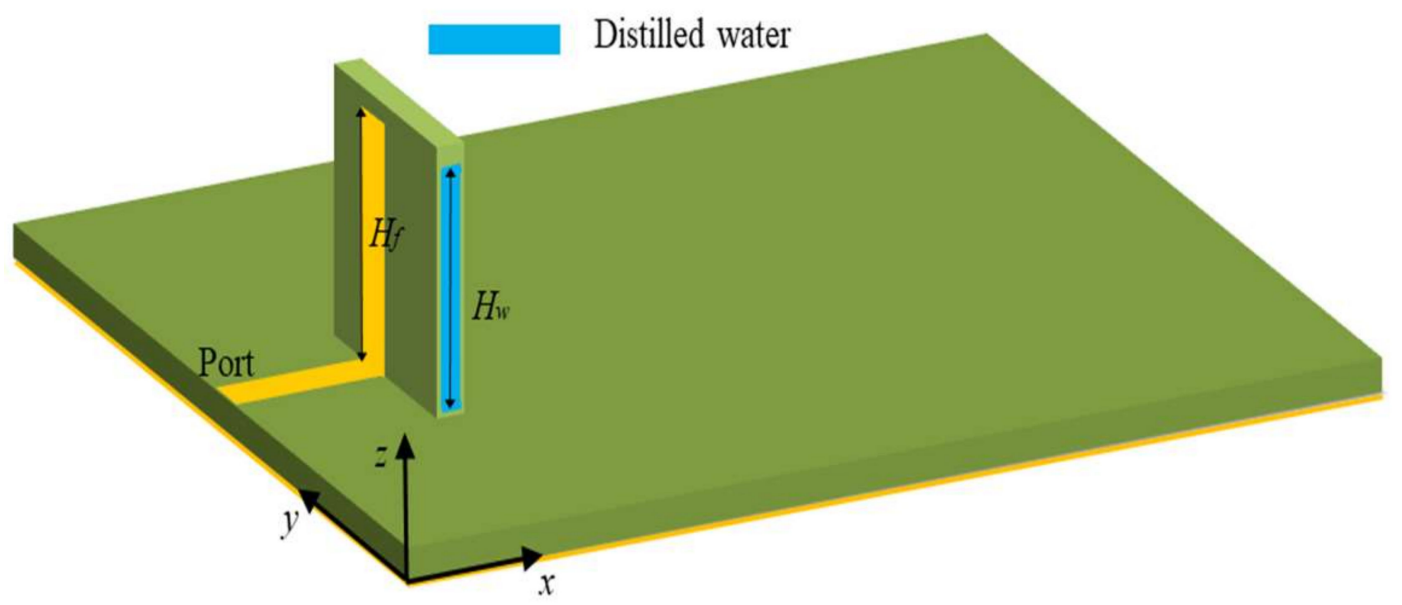

Figure 2. Simulation model of the hybrid water DRA.

One should note that, for the hybrid DRA proposed in this work, the function of adopting L-shaped metallic strip is not only for antenna excitation, but also enhancing antenna radiation performance. To evaluate the effects of the L-shaped metallic strip, the simulated reflection coefficients with different values of $H_{f}$ are analyzed. Two cases of the hybrid water DRA loaded with or without water are investigated. When the hybrid water DRA is unloaded with distilled water, namely $H_{w}=0 \mathrm{~mm}$, it is defined as State 1 . While the hybrid water DRA is loaded with a certain level of distilled water, i.e., $H_{w}=8 \mathrm{~mm}$, the state is defined as State 2. Figure 3a shows the reflection coefficient of State 1, it can be observed that as the parameter $H_{f}$ tuned from $8 \mathrm{~mm}$ to $12 \mathrm{~mm}$ with a step increment of $2 \mathrm{~mm}$, the center resonant frequency varies from $7.6 \mathrm{GHz}$ to $5.5 \mathrm{GHz}$. The phenomenon can be understood that the L-shaped metallic strip acts as a monopole antenna, and increasing the height of the vertical part $\left(H_{f}\right)$ is equivalent to increase the electrical length of the monopole antenna. Therefore, the resonant frequency could be shifted downwards. Figure $3 \mathrm{~b}$ shows the reflection coefficient of State 2 . When the parameter $H_{f}$ is varied from $8 \mathrm{~mm}$ to $12 \mathrm{~mm}$, the center resonant frequency decreases from $5.1 \mathrm{GHz}$ to $4.8 \mathrm{GHz}$. Compared to State 1, the center resonant frequency of State 2 has been shifted to lower frequency obviously because of adding the high permittivity materials of distilled water.

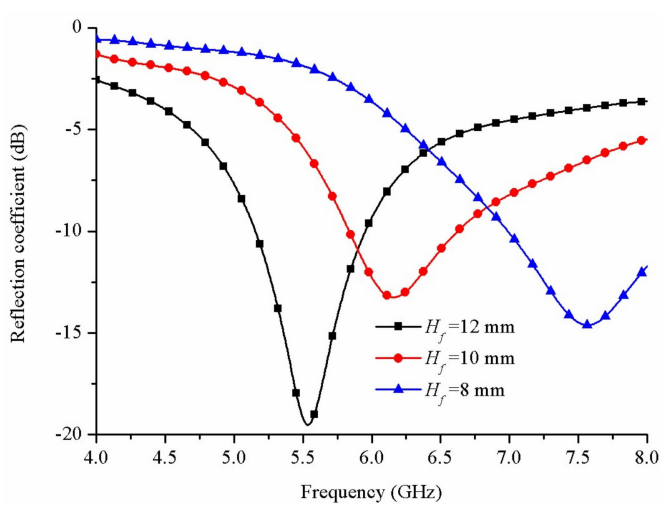

(a)

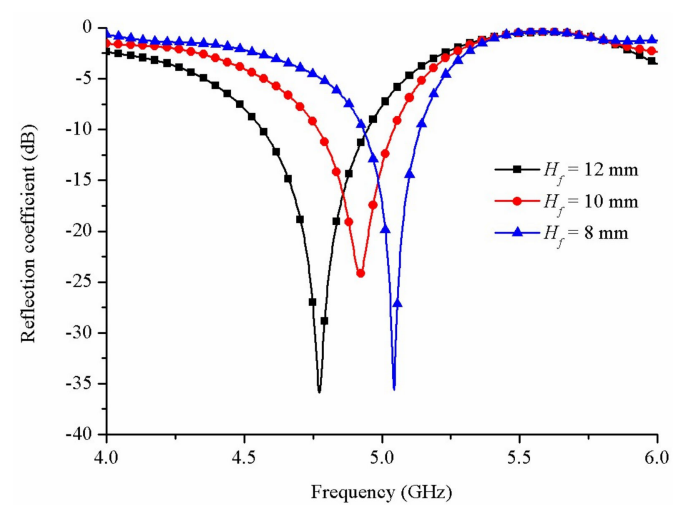

(b)

Figure 3. Simulated reflection coefficients for the two states: (a) State 1; (b) State 2.

In order to realize the frequency tunable of the proposed antenna, the effect of distilled water on the resonant frequency is investigated. Figure 4 shows the simulated reflection coefficients for different values of $H_{w}$. As seen from the figure, when tuning the parameter $H_{w}$ from $4 \mathrm{~mm}$ to $8 \mathrm{~mm}$ with a step increment of $2 \mathrm{~mm}$, the resonant frequency shifts down to lower frequency from $5.6 \mathrm{GHz}$ to $4.8 \mathrm{GHz}$. This result indicates that the distilled water has the function of reducing the resonant 
frequency effectively. Besides, one can observe that, by adjusting the height of the distilled water in the water DRA, the operating frequency would be affected obviously. Moreover, it is quite easy to adjust the height of distilled water by using a pressure controlling system because of its natural fluid properties.

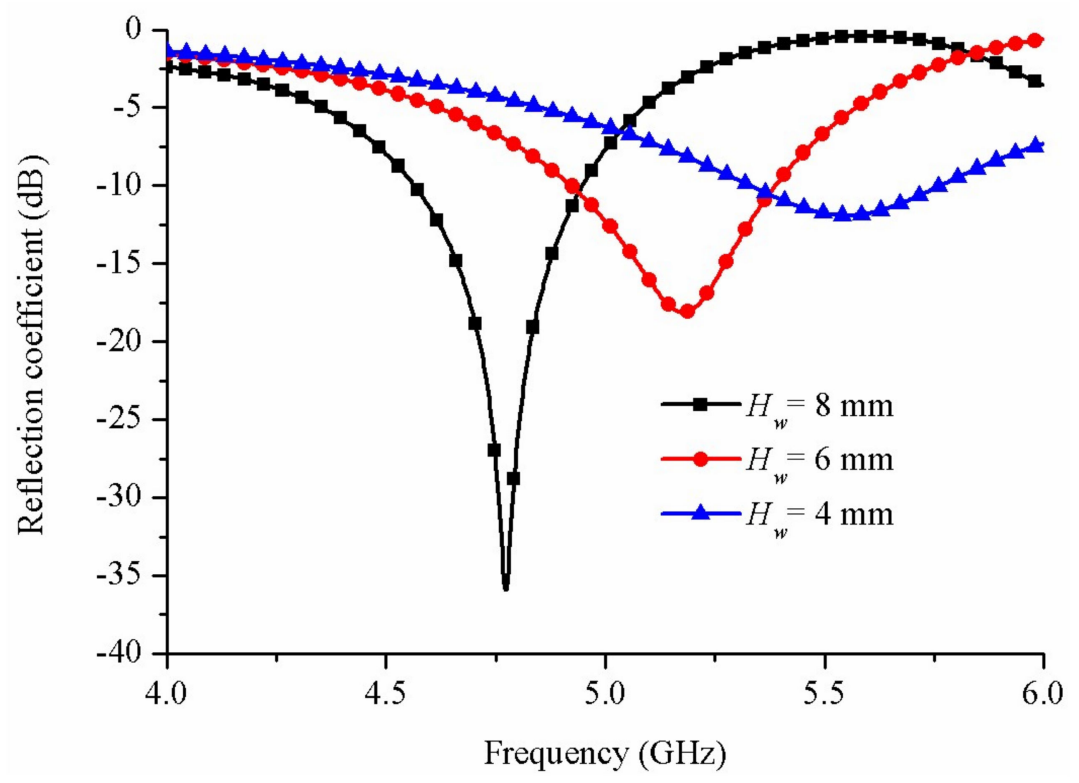

Figure 4. Simulated reflection coefficients for different values of $H_{w}$.

\subsection{Realization of Beamwidth Tuning}

In Section 3.1, the hybrid water DRA (driven element) with frequency tunable characteristic has been realized. To further obtain a beamwidth tunable performance, the radiation patterns of the proposed hybrid water DRA system (see Figure 1) is investigated in this subsection. As the driven element is vertically fed referenced to the ground plane, it has a small tilt angle with reference to the plane of the substrate. In order to adjust the beamwidth, director elements are introduced as shown in Figure 1. There are five director elements (named D1, D2, D3, D4, D5) mounted linearly with respect to the driven element. The space between the driven element and the first director element D1 is optimized to $3.5 \mathrm{~mm}$ while that between adjacent director elements is set to $d$, which is one of the key parameters influencing the beamwidth. In order to provide a more intuitive way to understand the operating mechanism of the director elements, parametric studies are performed as follows.

Supposing each director element has two switched states: "On" and "Off". "On" refers to the state that the director element is loaded with water; while the director element is unloaded with water, the state is defined as "Off". Therefore, 32 cases are obtained by selecting different combination of director elements. As a proof-of-concept demonstration, only three cases are considered, as tabulated in Table 1. For Case 1, only director element D1 is set to "On"; for Case 2, director element D1, D2 and D3 are set to "On" while D4 and D5 are set to "Off"; for Case 3, all director elements are set to "On".

Table 1. Three cases under different director elements combination.

\begin{tabular}{llllll}
\hline Status & D1 & D2 & D3 & D4 & D5 \\
Case 1 & On & Off & Off & Off & Off \\
Case 2 & On & On & On & Off & Off \\
Case 3 & On & On & On & On & On \\
\hline
\end{tabular}

Figure 5 shows the simulated 2-D radiation patterns with $d=2 \mathrm{~mm}$ under the three cases. One can observe that, in Case 1, the hybrid water DRA has a directional radiation pattern with a tilt angle about $60^{\circ}$ and $3-\mathrm{dB}$ beamwidth about $130^{\circ}$. For Case 3, the beamwidth becomes $80^{\circ}$ and the main 
beam is steering along $+x$-axis. It can be explained that more director elements (loaded with water) the antenna has, more electromagnetic energy are guided to the $+x$-axis direction. The working principle is similar to a Yagi antenna. Figure 6 shows the reflection coefficients corresponding to three cases. In Case 1, there are two resonant modes from $4 \mathrm{GHz}$ to $6 \mathrm{GHz}$. In particular, a deep resonance can be observed at $4.8 \mathrm{GHz}$. As the director elements (loaded with water) increases (Case 2 and Case 3), the resonant depth at lower frequency goes higher and a small frequency shift appears. These results indicate that the beamwidth can be tuned by controlling the number of director elements (loaded with water) though there is a certain effect on the impedance performance.

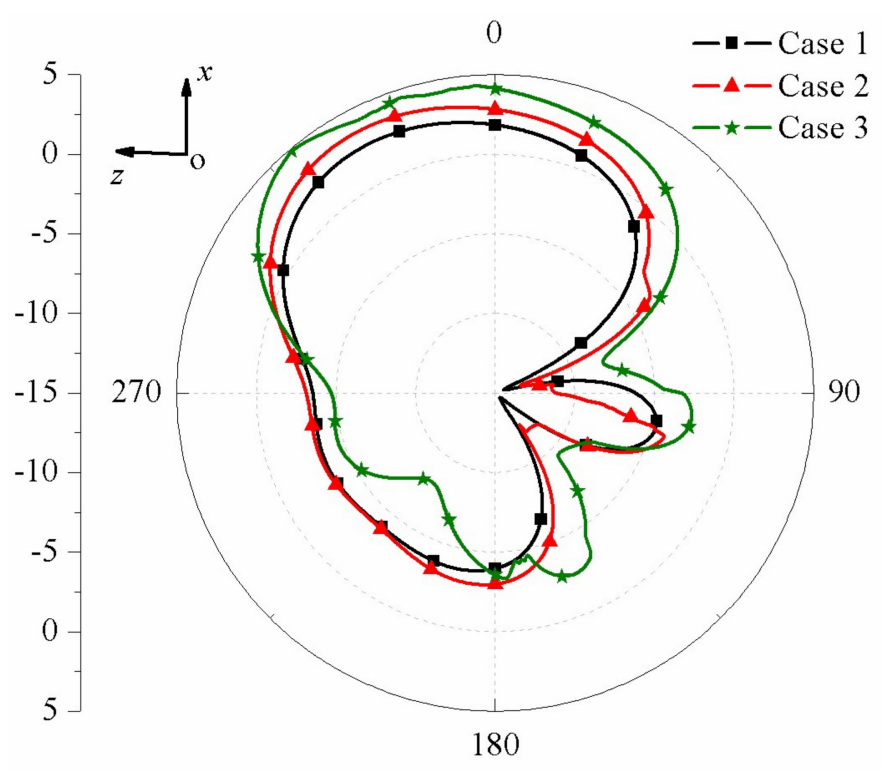

(a)

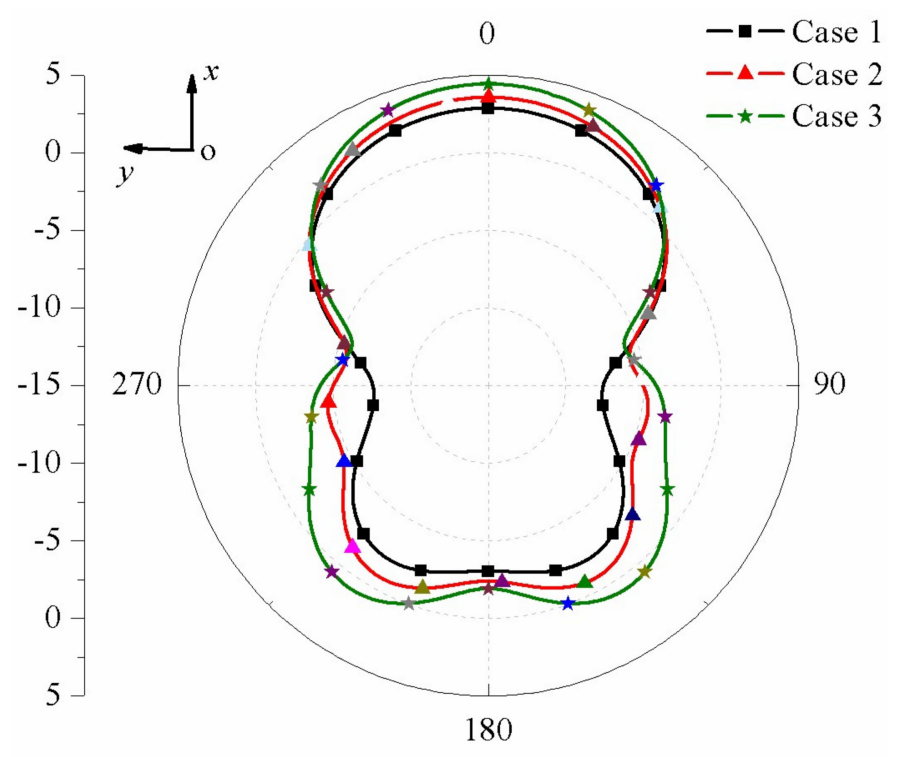

(b)

Figure 5. Simulated 2-D radiation patterns with $d=2 \mathrm{~mm}$ for the three cases. (a) xoz-plane; (b) xoy-plane. 


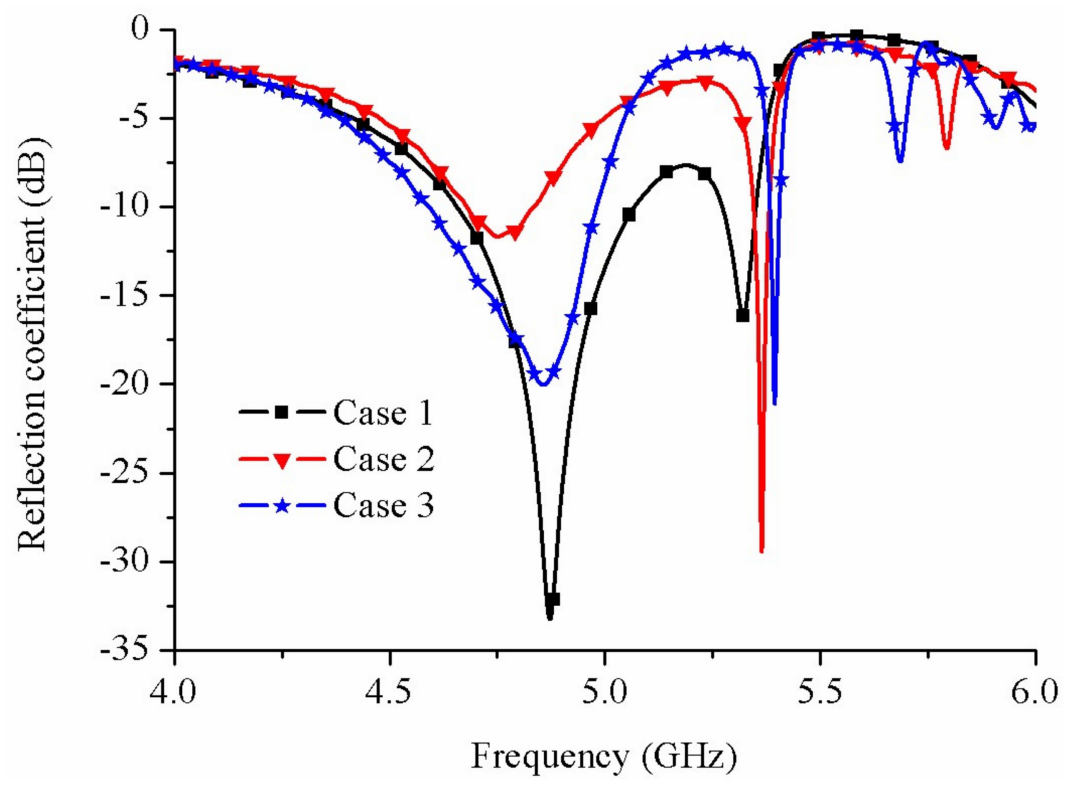

Figure 6. Simulated reflection coefficients with $d=2 \mathrm{~mm}$ for the three cases.

Figure 7 shows the simulated 2-D radiation patterns with $d=3 \mathrm{~mm}$ under the same cases. It can be seen that the tilt angle also increases with the increase of director elements (loaded with water). Compared to Figure 5, the main beam is not able to steer along $+x$-axis anymore if the number of director elements (loaded with water) increases to five (Case 3). Figure 8 shows the reflection coefficients of the corresponding cases with $d=3 \mathrm{~mm}$. It is obvious that there are only one resonant mode from $4 \mathrm{GHz}$ to $6 \mathrm{GHz}$, and the center resonant frequency keeps unchanged when the director elements (loaded with water) increase.

It can be summarized with reference to Figures 5 and 7 that when the number of director elements (loaded with water) can be controlled by injecting or evacuating water, the beamwidth tunable characteristic can be achieved. Taking the case that the main beam is able to steer along $+x$-axis with $d=2 \mathrm{~mm}$ as an example, the antenna will be fabricated and presented in next section while considering its optimal directional performance. Also, a gain enhancement by more than $0.5 \mathrm{~dB}$ is observed when the director elements (loaded with water) increase to five.

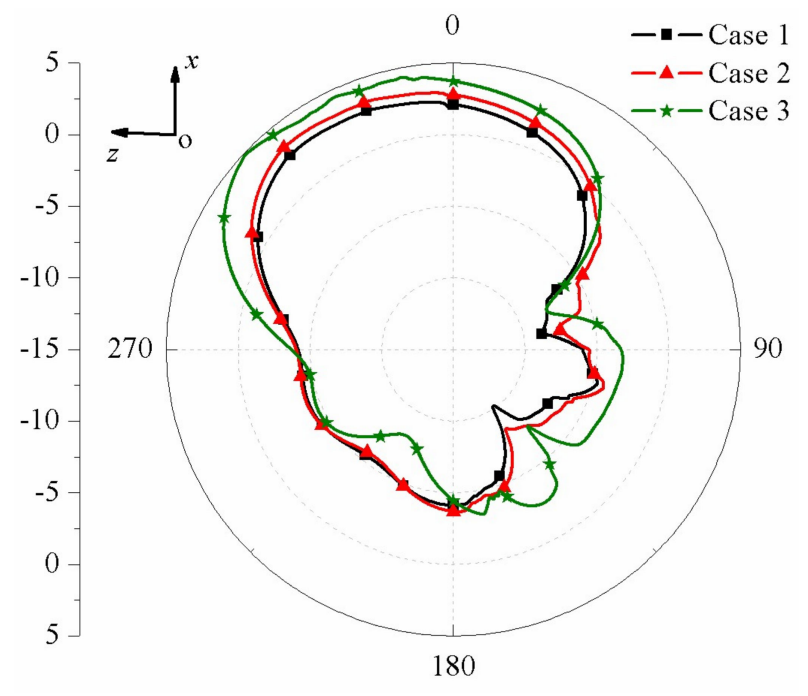

(a)

Figure 7. Cont. 


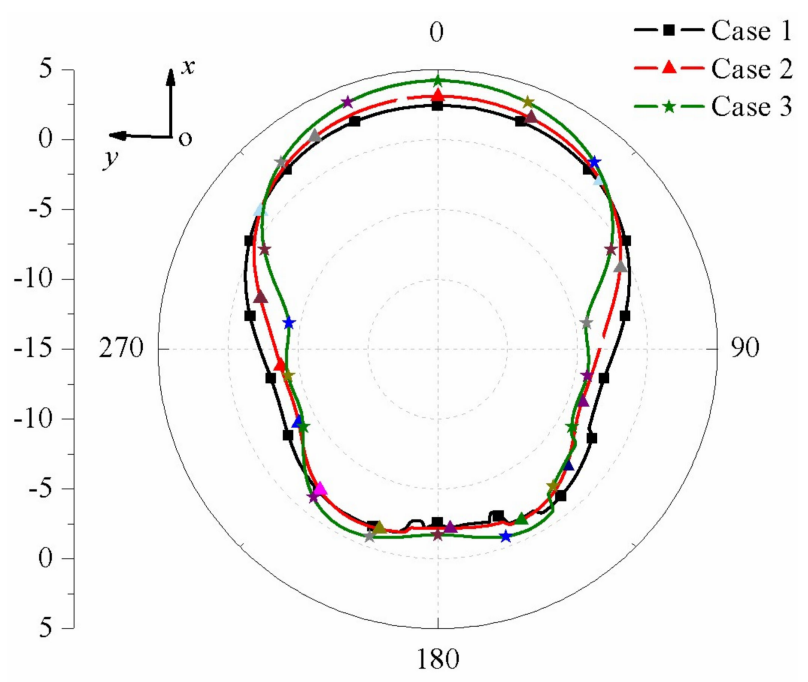

(b)

Figure 7. Simulated 2-D radiation patterns with $d=3 \mathrm{~mm}$. (a) xoz-plane; (b) xoy-plane.

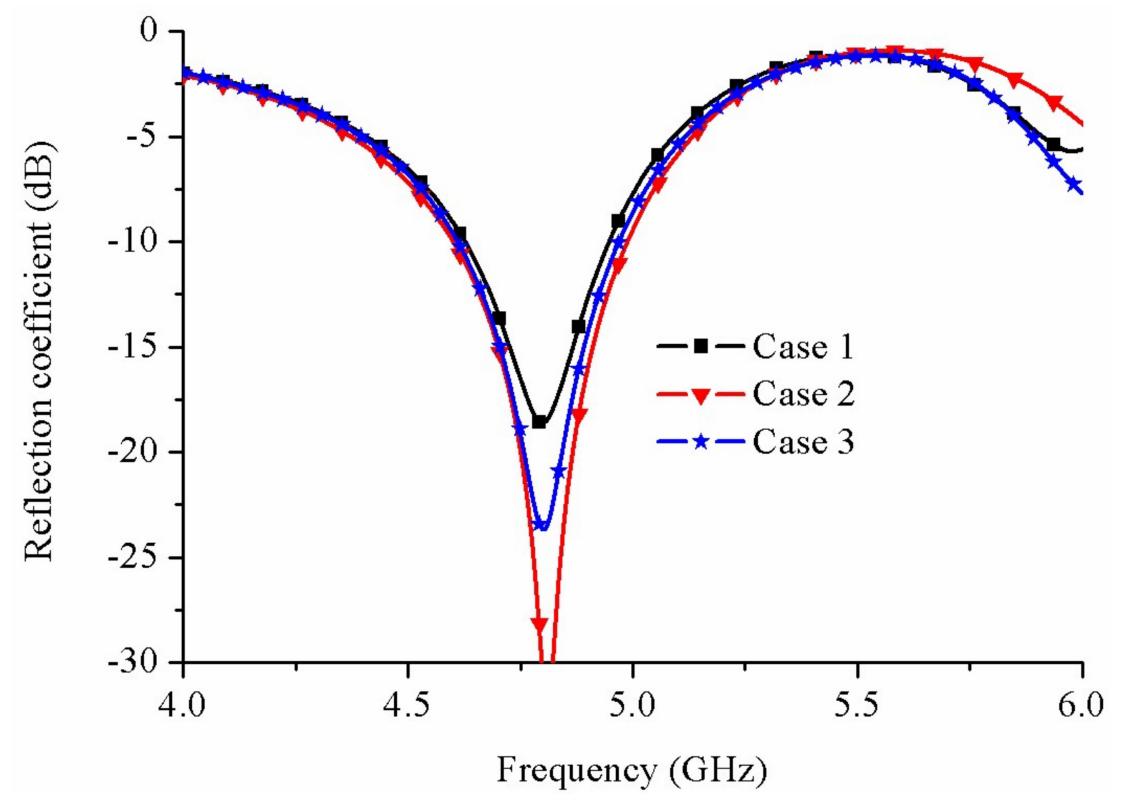

Figure 8. Simulated reflection coefficients with $d=3 \mathrm{~mm}$.

\section{Fabrication and Measurement}

The fabricated prototype of the proposed antenna is shown in Figure 9. The antenna is fed by a coaxial cable with an SMA connector connected to the 50 Ohms micro-strip feed line. The prototype is fabricated by using 3-D printing technology. The ground plane and the L-shaped strip feeder are realized by using adhesive copper tape. The water is pumped in and pumped out by using small syringes. 


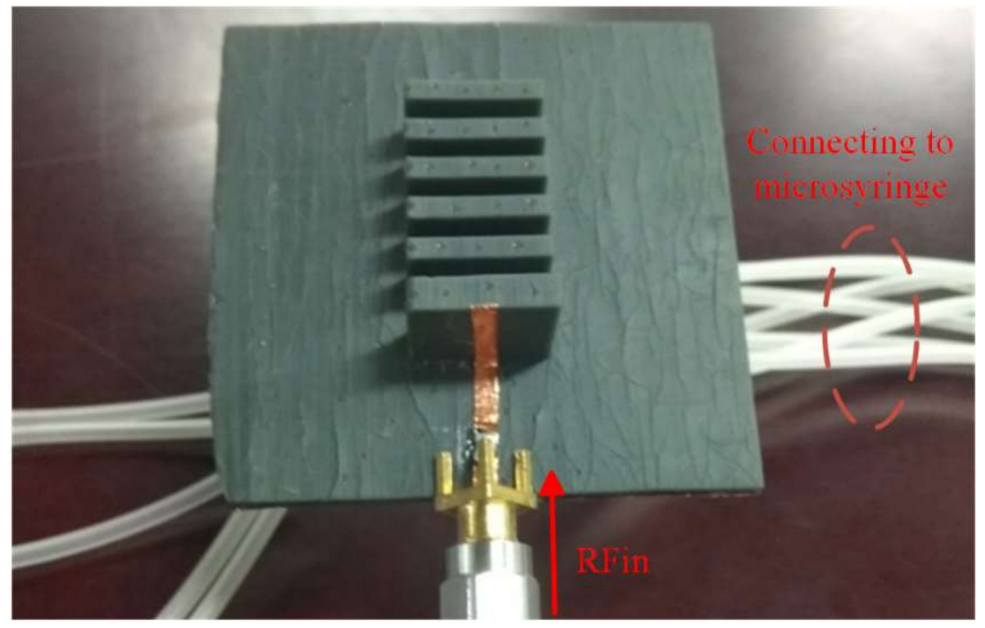

Figure 9. Fabricated prototype of the proposed antenna.

Figure 10 shows the measured reflection coefficients for different values of $H_{w}$. When $H_{w}=0$, the proposed antenna has an initial resonant frequency at $5.65 \mathrm{GHz}$; when turning the parameter $H_{w}$ from $4 \mathrm{~mm}$ to $10 \mathrm{~mm}$, the resonant frequency shifts down to lower frequency from $5.42 \mathrm{GHz}$ to $4.66 \mathrm{GHz}$. The results indicate that the distilled water has the function of reducing the resonant frequency effectively. Besides, one can observe that by adjusting the height of the distilled water in the water DRA, it can also change the operating frequency obviously. In addition, the height of distilled water is easily adjusted by using the pressure controlling system.

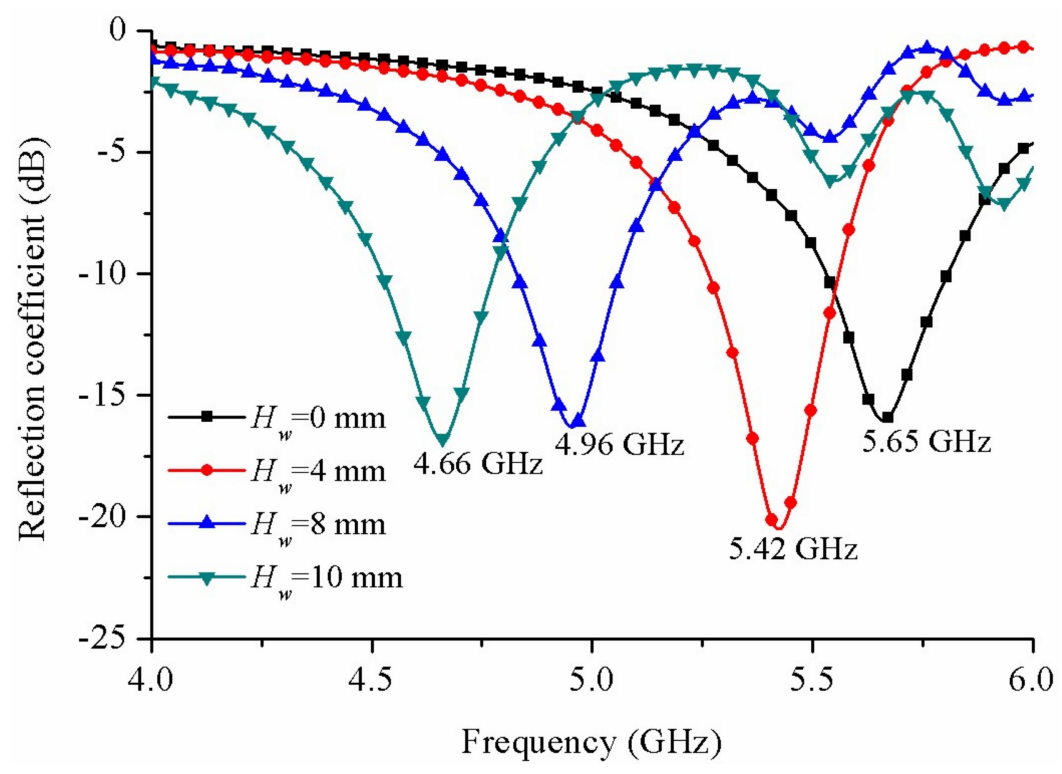

Figure 10. Measured reflection coefficients with different values of $H_{w}$.

Figure 11 shows the simulated (Sim.) and measured (Mea.) total efficiencies across the required bands with different values of $H_{w}$. As can be seen, the more water it is filled with, the lower the efficiency will be. The average simulated and measured total efficiencies are both larger than $64 \%$ when $4 \mathrm{~mm} \leq H_{w} \leq 10 \mathrm{~mm}$. However, when $H_{w}=0 \mathrm{~mm}$, meant that no distilled water is loaded in the driven element, the total efficiency is around $81 \%$. It can be explained that the distilled water could slightly degrade the efficiency due to its loss characteristics. Reasonable agreement between the simulation and measurement is revealed. 


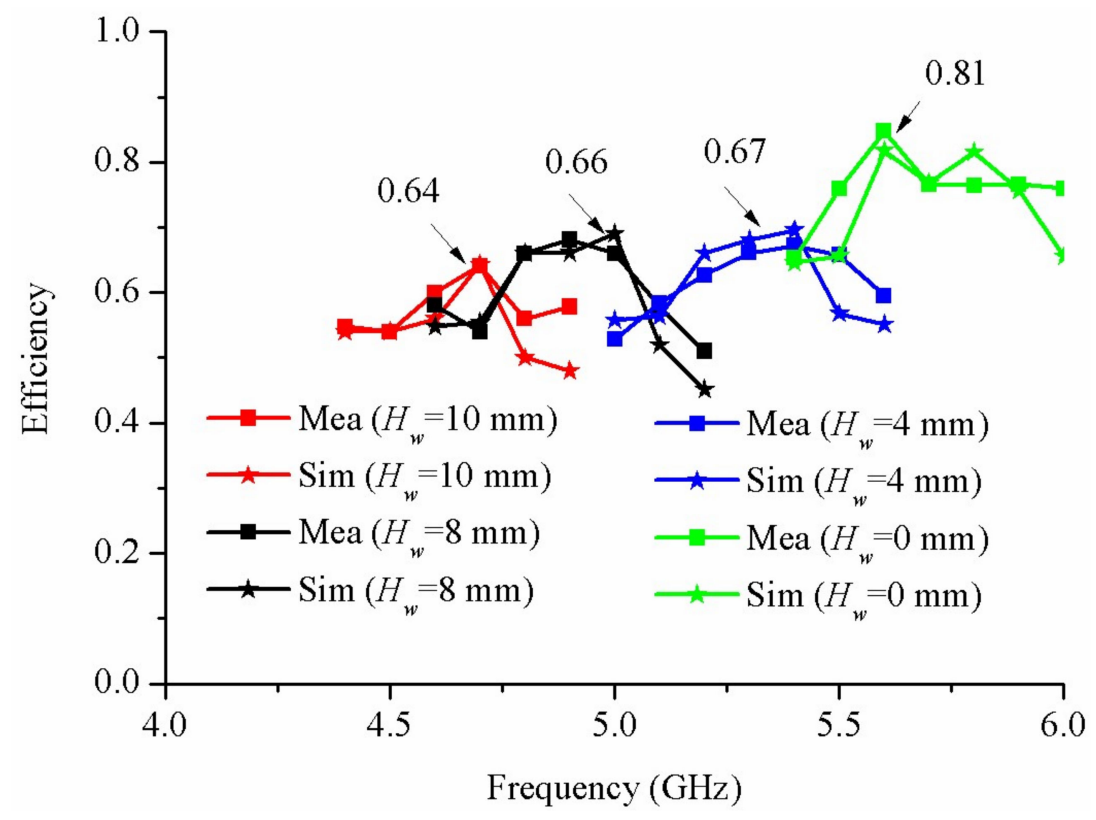

Figure 11. Simulated and measured efficiencies with different values of $H_{w}$.

The measured reflection coefficients for the three cases mentioned in Section 3.2 are shown in Figure 12. It can be seen that the center resonant frequencies of Case 1, Case 2 and Case 3 are $4.48 \mathrm{GHz}, 4.36 \mathrm{GHz}$ and $4.27 \mathrm{GHz}$, respectively, which are very close to the simulated results as shown in Figure 5. Minor deviation may be traced to the manually operated syringe system and the tolerances caused by the manufacturing process.

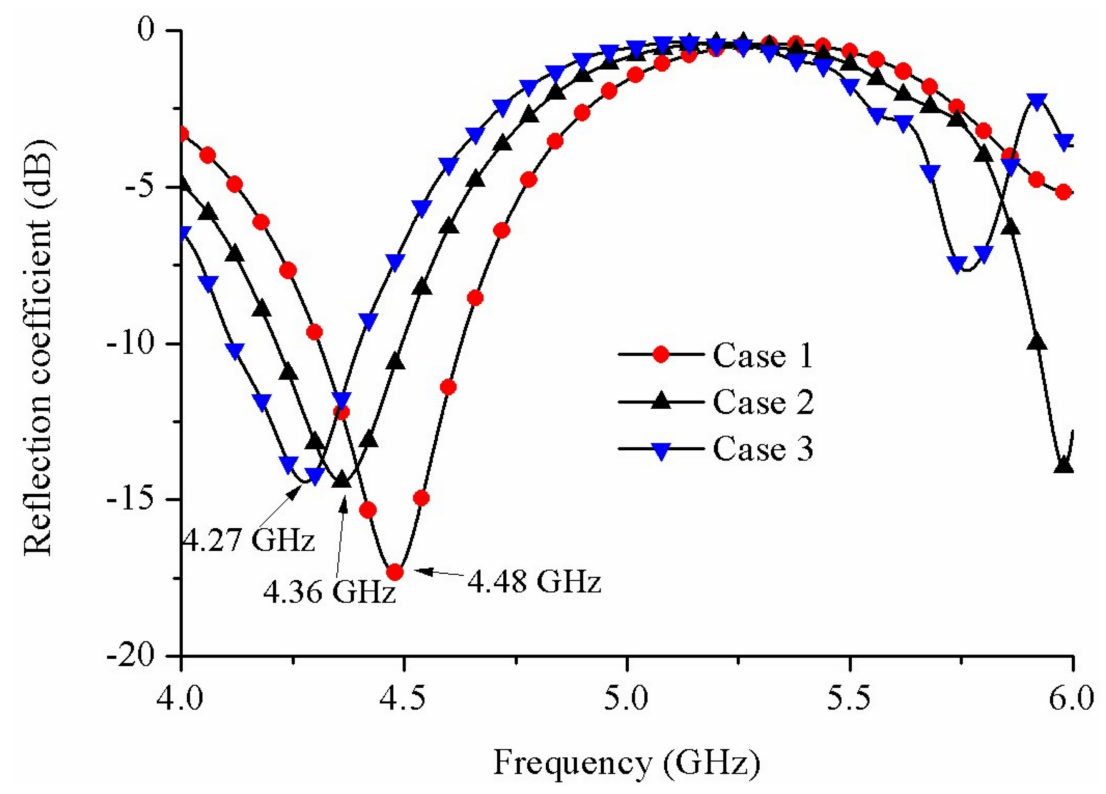

Figure 12. Measured reflection coefficients for the proposed three cases.

Figure 13 shows the simulated (Sim.) and measured (Mea.) total efficiencies of the proposed three cases. One can observe that the average simulated and measured total efficiencies are both larger than $61 \%$ across the required bands. 


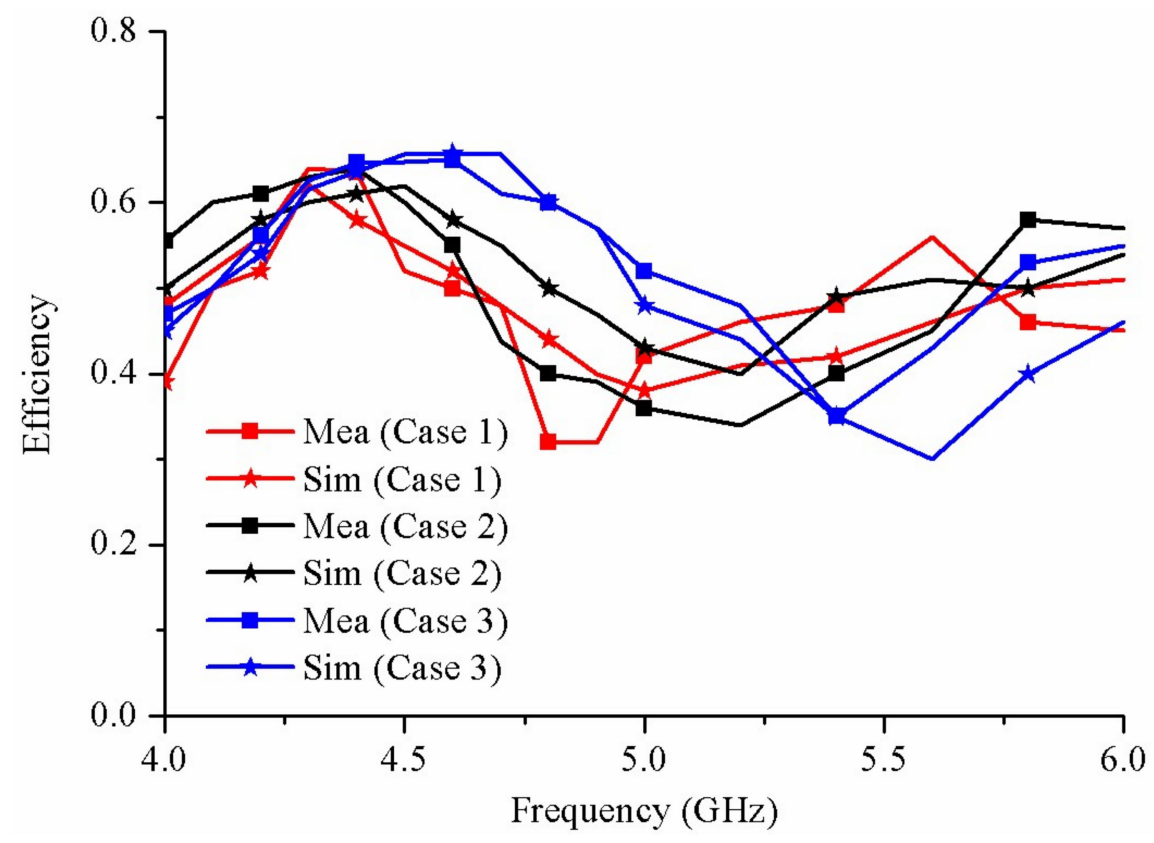

Figure 13. Simulated and measured efficiencies for the proposed three cases.

The radiation patterns of the proposed antenna have been measured in an anechoic chamber. Figure 14 depicts the measured far-filed gain patterns for Case 1, Case 2 and Case 3, respectively. It is obvious that the proposed antenna can generate three directional patterns on $x o z$-plane and xoz-plane. For the three cases, the measured maximum radiation direction is orienting to boresight direction, i.e., around $0^{\circ}$ along $+x$-axis, with different peak gains and different beamwidths. The maximum peak gain of $4.1 \mathrm{dBi}$ is obtained for Case 3 while the minimum peak gain of $3.6 \mathrm{dBi}$ appears in Case 1, showing that a beam steering along a fixed direction with a gain variation within $0.5 \mathrm{~dB}$ could be obtained.

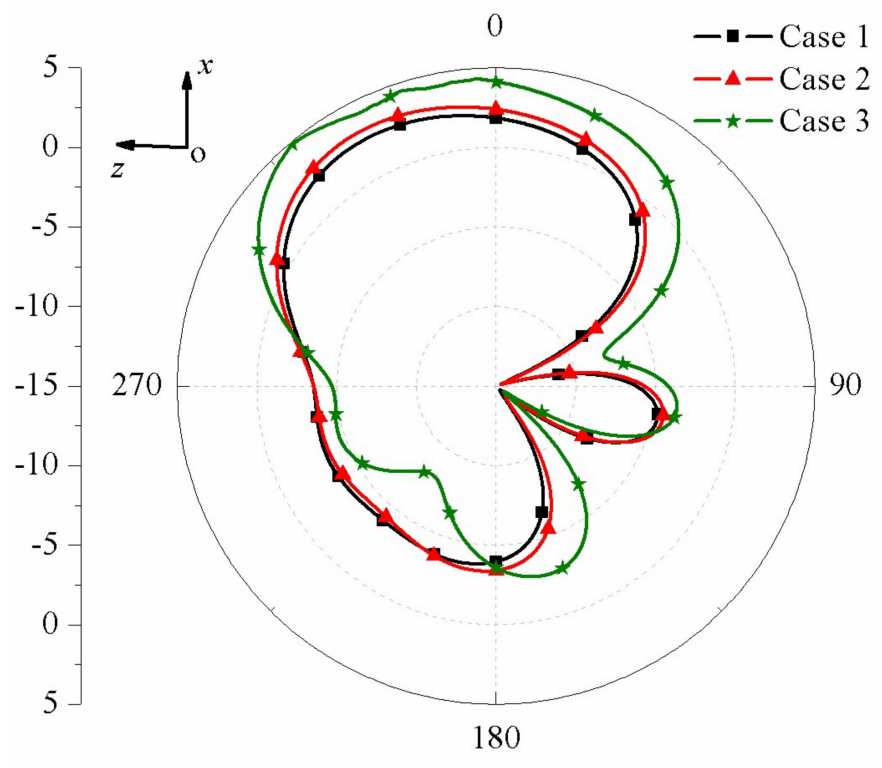

(a)

Figure 14. Cont. 


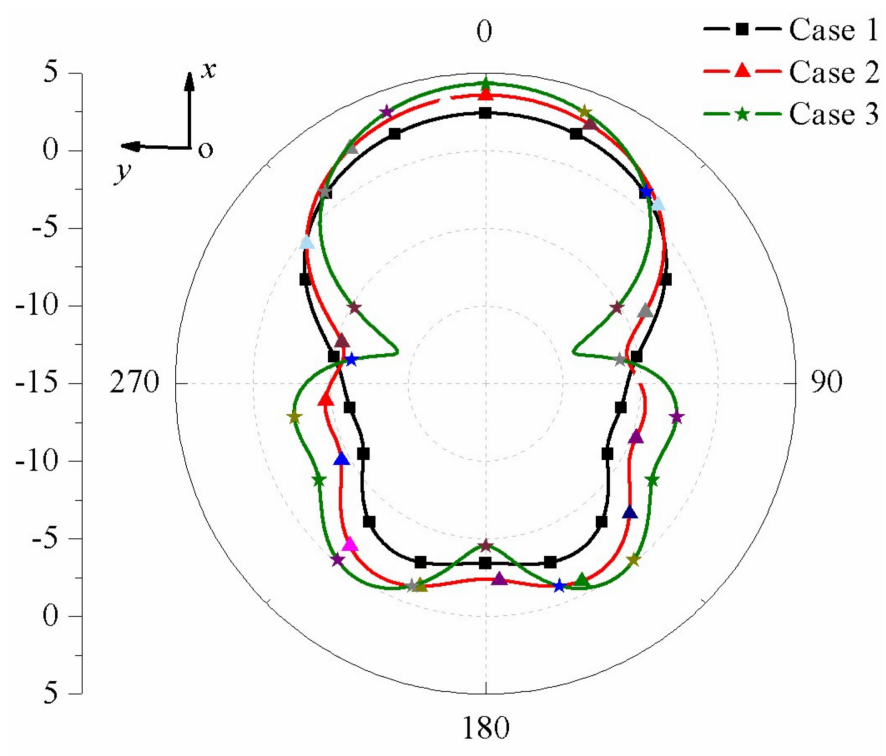

(b)

Figure 14. Measured radiation patterns for the proposed three cases. (a) xoz-plane; (b) xoy-plane.

\section{Conclusions}

A novel hybrid water antenna with tunable frequency and beamwidth characteristic was proposed in the work. The antenna utilizes an L-shaped strip feeder to effectively broaden the operating bandwidth. The L-shaped strip feeder and a rectangular water dielectric resonator constitute the driven element. Five identical rectangular water dielectric elements acting as the directors are mounted along with the driven element, which have the function of narrowing the beamwidth and increasing the gain. By varying the height of the liquid water injected in the driven element, the proposed antenna is able to operate at different frequencies. Meanwhile, by varying the number of director elements, the proposed antenna has the capability to tune to different beamwidths and gains. A prototype was fabricated by using 3-D printing technology to verify the design concept. Measured results agree well with the simulated ones. A tunable frequency range from $4.66 \mathrm{GHz}$ to $5.65 \mathrm{GHz}$ and a beam steering along a fixed direction with a gain variation within $0.5 \mathrm{~dB}$ are obtained.

Author Contributions: Conceptualization, Z.-P.Z. and J.-J.L.; Supervision, G.-L.H. and T.Y.; Writing-review \& editing, Z.-P.Z. and J.-J.L.

Funding: This work was supported in part by National Natural Science Foundation of China (No. 61801300 and No. 61701320), State Key Laboratory of Millimeter Waves Grant (K201932), Shenzhen Science and Technology Grant (JCYJ20170818101347761) and New Teacher Natural Science Research Project of Shenzhen University (No. 2018078).

Conflicts of Interest: The authors declare no conflict of interest.

\section{References}

1. Vipiana, F.; Vecchi, G.; Sabbadini, M. A Multiresolution Approach to Contoured-Beam Antenna. IEEE Trans. Antennas Propag. 2007, 55, 684-697. [CrossRef]

2. Vipiana, F.; Pirinoli, P.; Vecchi, G. Wavelet-MoM analysis of 3D antennas with triangular mesh. IEEE Trans. Antennas Propag. 2004, 2, 1471-1474.

3. Guariglia, E. Entropy and Fractal Antennas. Entropy 2016, 18, 84. [CrossRef]

4. Guariglia, E. Harmonic Sierpinski Gasket and Applications. Entropy 2018, 20, 714. [CrossRef]

5. Li, Y.; Luk, K.-M. A water dense dielectric patch antenna. IEEE Access 2015, 3, 274-280. [CrossRef] 
6. Hua, C.; Shen, Z.; Lu, J. High-efficiency sea-water monopole antenna for maritime wireless communications. IEEE Trans. Antennas Propag. 2014, 62, 5968-5973. [CrossRef]

7. Fan, R.-G.; Chu, Q.-X. A slot-coupled water-based stacked-patch antenna for wireless communications. In Proceedings of the 2017 IEEE International Conference on Computational Electromagnetics (ICCEM), Guangzhou, China, 23-25 February 2016; pp. 307-309.

8. $\quad$ Liang, J.-J.; Huang, G.-L; Qian, K.-W.; Zhang, S.-L.; Yuan, T. An Azimuth-Pattern Reconfigurable Antenna Based on Water Grating Reflector. IEEE Access 2018, 6, 34804-34811. [CrossRef]

9. Xing, L.; Huang, Y.; Xu, Q.; Alja'afreh, S. A wideband hybrid water antenna with an F-shaped monopole. IEEE Access 2015, 3, 1179-1186. [CrossRef]

10. Xing, L.; Huang, Y.; Xu, Q.; Alja'afreh, S.; Liu, T. A broadband hybrid water antenna for hand-portable applications. IEEE Antennas Wirel. Propag. Lett. 2016, 15, 174-177. [CrossRef]

11. Xing, L.; Huang, Y.; Xu, Q.; Alja'afreh, S.; Liu, T. Complex permittivity of water-based liquids for liquid antennas. IEEE Antennas Wirel. Propag. Lett. 2016, 15, 1626-1629. [CrossRef]

12. Qian, Y.-H.; Chu, Q.-X. A pattern-reconfigurable water-loaded MIMO antenna. Microwave Opt. Technol. Lett. 2017, 59, 1608-1613. [CrossRef]

13. Nishamol, M.S.; Sarin, V.P.; Tony, D.; Aanandan, C.K.; Pezholil, M.; Kesavath, V. An Electronically Reconfigurable Microstrip Antenna With Switchable Slots for Polarization Diversity. IEEE Trans. Antennas Propag. 2011, 59, 3424-3427. [CrossRef]

14. Sun, C.; Zheng, H.; Zhang, L.; Liu, Y. A Compact Frequency-Reconfigurable Patch Antenna for Beidou (COMPASS) Navigation System. IEEE Antennas Wirel. Propag. Lett. 2014, 13, 1626-1629.

15. Konca, M.; Warr, P.A. A frequency-reconfigurable antenna architecture using dielectric fluids. IEEE Trans. Antennas Propag. 2015, 63, 5280-5286. [CrossRef]

16. Saghati, A.P.; Batra, J.S.; Kameoka, J.; Entesari, K. A microfluidically reconfigurable dual-band slot antenna with a frequency coverage ratio of 3:1. IEEE Antennas Wirel. Propag. Lett. 2016, 15, 122-125. [CrossRef]

17. Morishita, A.M.; Kitamura, C.K.Y.; Ohta, A.T.; Shiroma, W.A. A liquid-metal monopole array with tunable frequency, gain, and beam steering. IEEE Antennas Wirel. Propag. Lett. 2013, 12, 1388-1391. [CrossRef]

18. Barrera, J.D.; Huff, G.H. A fluidic loading mechanism in a polarization reconfigurable antenna with a comparison to solid state approaches. IEEE Trans. Antennas Propag. 2014, 62, 4008-4014. [CrossRef]

19. Huang, G.-L.; Zhou, S.-G.; Yuan, T. Design of a Compact Wideband Feed Cluster With Dual-Polarized Sumand Difference-Patterns Implemented via 3-D Metal Printing. IEEE Trans. Ind. Electron. 2018, 65, 7353-7362. [CrossRef]

20. Huang, G.-L.; Zhou, S.-G.; Chio, T.-H; Yeo, T. Fabrication of a High-Efficiency Waveguide Antenna Array via Direct Metal Laser Sintering. IEEE Antennas Wirel. Propag. Lett. 2016, 15, 622-625. [CrossRef]

21. Huang, G.-L.; Zhou, S.-G.; Sim, C.-Y.-D.; Chio, T.-H.; Yuan, T. Lightweight Perforated Waveguide Structure Realized by 3-D Printing for RF Applications. IEEE Trans. Antennas Propag. 2017, 65, 3897-3904. [CrossRef]

22. Gowers, S.A.N.; Curto, V.F.; Seneci, C.A.; Wang, C.; Anastasova, S.; Vadgama, P.; Yang, G.-Z.; Boutelle, M.G. 3D printed microfluidic device with integrated biosensors for online analysis of subcutaneous human microdialysate. Anal. Chem. 2015, 87, 7763-7770. [CrossRef] [PubMed]

(C) 2018 by the authors. Licensee MDPI, Basel, Switzerland. This article is an open access article distributed under the terms and conditions of the Creative Commons Attribution (CC BY) license (http://creativecommons.org/licenses/by/4.0/). 